\title{
SOBRE LOS OBJETOS ADECUADOS Y LA DIVISIÓN DE LAS CIENCIAS ESPECULATIVAS EN F. SUÁREZ: UNA INTERPRETACIÓN LITERAL DE LAS DISPUTATIONES METAPHYSICAE I, I, 14-15
}

\author{
Jose Maria Felipe Mendoza \\ bttps://orcid.org/0000-0002-1881-0947 \\ Universidad Nacional de Cuyo \\ Consejo Nacional de Investigaciones Científicas y Técnicas \\ https://doi.org/10.15304/ag.40.1.6651
}

\section{Resumen}

De acuerdo con el comienzo de las D.M. de Francisco Suárez, la ciencia metafísica ha perdido su horizonte. No hay claridad sobre qué asuntos trata ni cuál es el modo más apropiado para considerarlos. Por esta razón el tratado capital del Dr. Eximio principia con un estudio sustancial de la filosofía primera donde paulatinamente se atenderán las dificultades emergentes relativas a una consideración adecuada de las ciencias en su totalidad, y a las especulativas en particular. De ese modo, y según el sentir de Suárez, la claridad meridiana alcanzada en derredor de la metafísica colocaría las bases necesarias para evitar -o tratar de corregir- los errores en teología sagrada, ya considerada en sí misma, ya por su vinculación necesaria con la filosofía primera. Asimismo, el esclarecimiento del objeto adecuado de la metafísica conlleva la necesidad de evidenciar para la razón aquellos propios de las demás ciencias, configurándose así una división y relación armónica entre las ciencias especulativas en sede objetiva. A su vez este panorama particular aparece expresado con total claridad en las D.M. I, I, 14-15 sobre el que exclusivamente se hará foco.

Palabras clave: Francisco Suárez, objeto adecuado, metafísica, ciencias especulativas, abstracción formal.

Recibido: 05/03/2020. Aceptado: 30/06/2020. 


\begin{abstract}
According to the beginning of Francisco Suarez's D.M., metaphysical science has lost its horizon. There is no clarity about which issues it deals with or which is the most appropriate way to approach them. For this reason, Dr. Eximio's main treatise begins with an essential study of the first philosophy where the emerging difficulties related to an adequate consideration of the sciences as a whole, and to the speculative ones in particular, will be gradually addressed. Thus, and according to Suarez's opinion, the absolute clarity reached around metaphysics lays the necessary foundations to avoid -or try to correct- errors in sacred theology, either considered in itself, or because of its necessary link with the first philosophy. Likewise, the clarification of the adequate object of metaphysics entails the need to evidence those of the other sciences, configuring a division and harmonious relationship between the speculative sciences objectively. At the same time, this particular panorama appears expressed with total clarity in the D.M. I, I, 14-15 on which exclusively it will be made focus.

Keywords: Francisco Suarez, adequate object, metaphysics, speculative sciences, formal abstraction.
\end{abstract}

Las Disputationes Metaphysicae de Francisco Suárez ${ }^{1}$ han sido objeto de múltiples consideraciones académicas en las últimas décadas del siglo $\mathrm{XXI}^{2}$ para medievalistas y estudiosos de la modernidad. Los primeros, por la misma filosofía del Dr. Eximio, ${ }^{3}$ quien manifiesta un amplísimo conocimiento

${ }^{1}$ El siguiente estudio está basado en la traducción de, Francisco Suárez, Disputaciones Metafísicas, Madrid, Biblioteca hispánica de filosofía, 1960. [Ed. y trad. de S. Rábade Romeo, S. Caballero Sánchez y A. Puigcerver Zanón]. Sin embargo cabe aclarar que se aparta sólo en escasos términos y en limitadas expresiones lingüísticas en razón de una mejor intelección de la lengua latina. Así, v.g., cuando el latín dice abstractio, intellectus o contemplatio, he preferido traducir abstracción, intelecto o contemplación, y no aquellos términos de prescindencia, razón, entendimiento, estudio o consideración según figuran en la traducción supra.

${ }^{2}$ M. Lázaro Pulido, M. Idoya Zorroza, "Memoria peninsular de un legado para el siglo XXI: Francisco Suárez (1617-2017)”, Pensamiento 74/279 (2018), 299-318.

${ }^{3}$ V. Sanz Santacruz, "Filosofía y teología en Francisco Suárez”, en Á. L. González (ed.), La intermediación de filosofía y teología. Santo Tomás de Aquino, San Buenaventura, Nicolás de Cusa, Suárez, Pamplona, Cuadernos de Anuario Filosófico n. 241, 2011, pp. 104-105: "El carácter de sistema que inauguran las Disputaciones Metafísicas de Francisco Suárez pone orden en el abigarrado entramado de glosas, comentarios, sumas y cuestiones medievales y contribuye, sin lugar a dudas, al considerable éxito que alcanzó la obra. Pero, al margen de la novedad de una manera de presentar el saber más organizada que los viejos usos de la tradición medieval, ya decadente, lo que interesa es descubrir la actitud de fondo que subyace en un asunto crucial, como es la relación entre filosofía y teología — abordada brevemente en los proemios a las D.M. - ." Nuestro interés está en la continuidad y extensión de esta apreciación a través de la noción de filosofía en F. Suárez. 
de la escolástica medieval y renacentista. ${ }^{4}$ En cambio los segundos, por la acentuada influencia de su pensamiento en la filosofía católica y protestante posterior. $^{5}$

La herencia intelectual recopilada en los textos del Granadino respecto de la Edad Media pone de manifiesto su deuda con la tradición aristotelizante del saber. ${ }^{6}$ Publicada en el año de 1597 en la Universidad de Salamanca, ${ }^{7}$ el tratado de las D.M. discutía en sus LIV libros qué es el ente, cómo debe entenderse su extensión conceptual, de qué modo es considerado por cada una de las ciencias, cuál es la implicancia de los principios metafísicos para los demás saberes demostrativos, y de qué modo Dios y las inteligencias quedan contenidas en la máxima ciencia racional, entre otras numerosas cuestiones. A su vez todas ellas propulsan la necesidad intelectual de precisar el conocimiento científico según la doctrina de cada ciencia. Mas, este último aspecto, que reúne y fundamenta los saberes y delimita su horizonte, no habría sido enfocado directa y exclusivamente por los estudiosos contemporáneos. La doctrina científica del Dr. Eximio parecería ser todavía en numerosos aspectos terra incognita.

${ }^{4}$ H. Pérez San Martín, "Cuestiones previas al estudio de las Disputaciones Metafísicas del P. Francisco Suárez”, Cuadernos Salmantinos de Filosofía 24 (1997), 48: “el P. Suárez logra confrontar la totalidad de las tesis escolásticas del pasado con los problemas y opiniones de su época, convirtiendo de este modo su corpus metafísico en una enciclopedia critica del saber filosófico [...]".

${ }^{5}$ J. Pereira, Suárez between Scholasticism and Modernity, Wisconsin, Marquette University Press, 2006, pp. 10-11; cfr. J. De Almeida Oliveira, "Francisco Suárez: a metafísica na aurora da modernidade", Theoria - Revista Eletrônica de Filosofia 2/4 (2010), 44-57; cfr. F. Suárez, Disputaciones Metafísicas, Madrid, Tecnos, 2011. [Presentación de S. Rábade Romeo y Estudio Preliminar de F. L. Florido], p. 37-49.

${ }^{6}$ E. Gilson, El ser y los filósofos, Pamplona, Eunsa, 1979, p. 156: “De hecho, Suárez goza de un conocimiento tal de la filosofía medieval como para avergonzar a cualquier historiador moderno del pensamiento medieval. En todas y cada una de las cuestiones parece conocerlo todo y a todo el mundo, y leer su libro es como asistir al Juicio Final de cuatro siglos de especulación cristiana por un juez desapasionado, deseoso siempre de dar a cada cual una oportunidad, supremamente apto para hacer el balance de un caso y, desafortunadamente, tan ansioso de no ofender a la equidad que, para él, un veredicto moderado es el más digno de ser considerado como veredicto verdadero".

7 J. R. Hale, La Europa del Renacimiento 1480-1520, Madrid, Siglo XXI, 2016, pp. 293-336; cfr. G. Parker, Europa en crisis 1598-1648, Madrid, Siglo XXI, 2017, pp. 354-373; cfr. F. J. Alejo Montes, "La Universidad de Salamanca en el s. XVI: la reforma educativa de D. Juan de Zuñiga (1594)", Studia histórica: Historia Moderna, 8 (2009), 151-162. Cfr. F. L. Florido, "El debate sobre la modernidad de la filosofía medieval", Cauriensia 12, (2017), 467-489; cfr. L. E. Rodríguez-San Pedro de Bezares, La Universidad Salmantina del Barroco, período 1598-1625, t. II: régimen docente y atmósfera intelectual, España, Universidad de Salamanca, 1986. 
La necesidad aludida de precisar el conocimiento científico deja entrever su actualidad como hombre del renacimiento español. ${ }^{8} \mathrm{La}$ discusión sobre el canon aristotélico de las ciencias, acontecida en el siglo XVI tiene ante sí dos frentes. Primero, en diálogo permanente con los escolásticos de los siglos XIII al XV, ${ }^{9}$ el Granadino fija una nueva comprensión sobre la doctrina de las ciencias a modo de respuesta ante las múltiples interpretaciones sobre la filosofía aristotélica, ${ }^{10} \sin$ dejar de señalar, seguidamente, que ello también respondería a la inclinación cada vez más evidente del pensamiento de la época en favor de una tendencia platonizante y matematizante del saber, como son los célebres casos de Copérnico, Bruno y Galileo entre muchos otros.

La novedad especulativa de Suárez, derivada de aquella necesidad señalada supra, se evidencia al interior del aristotelismo, en relación con la totalidad de las ciencias, al gravitar alrededor de las nociones de obiectum, conceptus entis, conceptus obiectivum, conceptus formalis y ens abstractissimum. En efecto, las D.M. manifiestan el surgimiento de una filosofía que reorganiza la glosa al tratado aristotélico de la Metafísica según los temas capitales del saber. En derredor de ello, la ciencia se configura en sede objetiva y conceptual. Esta es la novedad que ilustra uno de los giros especulativos determinantes entre la Edad Media y la Edad Moderna. ${ }^{11}$ Empero, todo ello aparece plasmado en una trama escolástica de horizontes científicos de características aristotélicas que es sede común entre la medievalidad y la modernidad. ${ }^{12}$ En el caso del Dr. Eximio esta tradición epistémica presentaría

${ }^{8}$ A. Guy, Historia de la filosofía española, Barcelona, Anthropos, 1985, pp. 108-117; cfr. C. Esposito, "Suárez, filósofo barroco", Cauriensia, 12 (2017), 25-42.

${ }^{9}$ Y. Guerrero Navarrete, "Los contenidos de la ciencia y los progresos de la ciencia en la Edad Media", Arbor CLIX/625 (1998), 82-84; cfr. A. C. Crombie, Historia de la ciencia: de San Agustín a Galileo/2, Madrid, Alianza, 1987.

10 Á. Poncela González, “Aristóteles y los Jesuitas. La génesis corporativa de los cursus philosphicus”, Cauriensia (2011), 65-101.

${ }^{11}$ J.-F. Courtine, Suarez et le système de la métaphysique, París, Épiméthée, 2015, pp. 12-41: Este capítulo, dedicado al tratamiento escolástico de la metafísica como ciencia, se detiene en la transformación de la noción de subiectum en obiectum. Sobre la base de numerosos textos que recorren principalmente las posiciones de Avicena, Tomás de Aquino y Duns Scoto, se busca mostrar el giro que comienza en la teología como sacra doctrina hasta su configuración como metafísica en un horizonte cada vez más racionalista. Mientras que la noción de subiectum designa la unidad de una ciencia per se, la noción de obiectum, en cambio, siempre enmarcada en un contexto noético, expresa la relación de la ciencia según la expresión quoad nos. Allí, en su configuración, interviene la inteligencia.

${ }^{12}$ E. Gilson, T. Langan, Filosofía Moderna, Barcelona, Emecé, 1963, pp. 3-7; cfr. C. Fabro, Historia de la Filosofía I, Madrid, Rialp, 1965, pp. 557-574; cfr. F. L. Florido, "Una estructura filosófica en Historia de la Filosofía”, Anales del Seminario de Historia de la 
cuatro hilos teoréticos: 1 . aristotelismo antiguo, medieval y renacentista, 2. Tomás de Aquino y el tomismo medieval de la primera escolástica, 3. la naciente segunda escolástica dominica. ${ }^{13}$

Bajo este marco el presente trabajo propone ${ }^{14}$ una introducción a la división de las ciencias especulativas en clave objetiva con especial énfasis en la metafísica, según aparece formulada por Suárez en las D.M. I, I, 14-15 en razón del siguiente considerando: la D.M. I está dirigida a ubicar adecuadamente la metafísica entre las ciencias, ${ }^{15}$ y junto con ello, el apartado

Filosofía 17 (2000), 195-216; cfr. F. L. Florido, Las filosofías en la Edad Media. Crisis, controversias y condenas, Madrid, Biblioteca Nueva, 2010, pp. 233-289. Después de la condena parisina de 1277 por Esteban Tempier, el aristotelismo se mantiene y, a la vez, se supera, en muchos casos, desde los mismos textos de Aristóteles. El s. XIV produce un cambio de enfoque en la realidad. Cambian principalmente los modos de comprensión de las ciencias especulativas de la física, la lógica y la metafísica. Aquí aparece con claridad el enfrentamiento entre los antiqui y los moderni. Esta revolución científica, donde Tomás de Aquino quedó entre los antiqui y Duns Scoto entre los moderni, junto con Ockham y Buridan, se prolongó en sus consecuencias para la teología y la filosofía posteriores, alcanzando tanto a Cayetano como a Suárez.

${ }^{13}$ S.-T. Bonino, “Avant-propos. Le thomisme et son historie”, R.T. 97 (1997), 5-8. Cfr. S.-T. Bonino, "L'école thomiste au XVe siècle", RTLu, V/2 (2000), 223-234. Cfr. S.-T. Bonino, "Le thomisme parisiena u XVe siècle", R.T. 107 (2007), 625-653; cfr. D. Lorenz, "Sobre algunos disensos, progresos y crisis en la historia de la metafísica tomista", Revista Philosophica 26 (2003), 1-16; cfr. L. Prieto López, "La impronta escotista en la metafísica de Suárez: conocimiento intuitivo, actualidad de la materia prima e hipostatización del accidente", Logos. Anales del seminario de Metafísica 50 (2017), 207-227.

${ }^{14}$ Los estudios sobre las D.M. de Francisco Suárez suelen ser escasos en comparación con filósofos y teólogos de su misma talla, entre los cuales hallamos, por ejemplo, a Duns Scoto, Tomás de Aquino y Kant. El Granadino, cierta y merecidamente ubicado entre ellos, dejó sus huellas en la filosofía trascendental kantiana, y asumió, a su modo, las filosofías escotista y tomasina en la configuración de su metafísica. Empero, si bien los escritos sobre su obra han ido revirtiendo el juicio inicial de modo gradual, lejos estamos aún de estudios sistemáticos respecto de la totalidad de su doctrina. Solemos considerar aspectos fundamentales de las D.M. en la búsqueda de su originalidad, equilibrando las influencias medievales y su transmisión a la consolidación de la metafísica moderna en las personas de Descartes y Leibniz entre otros, pero escasamente atendemos a los pilares fundamentales que enmarcan la ciencia metafísica de acuerdo con el modo de proceder del mismo Suárez.

${ }^{15}$ La primera sección de la D.M. I presenta seis opiniones sobre el objeto de la ciencia metafísica que con frecuencia se sostenían en el s. XVI. Tal disparidad de juicios, fundados todos ellos sobre hermenéuticas del tratado homónimo aristotélico y del devenir de una tradición cristiana aristotelizante, condujo a una inadecuada comprensión, según el parecer de Suárez, de dicho saber, y al riesgo, cada vez más próximo, de un cuestionamiento que interrogue sobre la auténtica utilidad de dicha ciencia en particular, tanto respecto de sí como para las restantes. No es transparente ni hay acuerdo sobre qué es la metafísica. Esto es sintomático, y es, en verdad, la razón por la que el tratado primero de las D.M. comienza de esa manera. No hubiera sido apropiada una declaración de principios de carácter absoluto y 
indicado muestra por vez primera cómo el Dr. Eximio asume el problema de la relación entre los saberes. De acuerdo con ello intentaremos iluminar tres cuestiones: 1 . una objeción presuntamente averroísta sobre el contenido de la ciencia metafísica; 2. el auténtico interés de Suárez sobre la división de las ciencias especulativas: una inadecuada comprensión del tratado de la Metafísica aristotélica; 3. la posición definitiva del Dr. Eximio sobre la máxima ciencia racional y sobre aquella división de las ciencias. ${ }^{16}$

\section{Una división inadecuada de las ciencias: el supuesto caso de Averroes y los saberes especulativos}

Francisco Suárez explicita por vez primera una división completa de las ciencias especulativas en las D.M. I, I, 14. Allí, de acuerdo con una objeción esgrimida sobre la presunta base de la posición filosófica de Averroes, la lectura de los pasajes esenciales sobre el modo de justificar el horizonte de cada ciencia resultaría confusa e inadecuada. La tesis de la objeción sostiene lo siguiente:

La cuarta opinión es, por consiguiente, que la sustancia o ente inmaterial, en cuanto que incluye en sí sólo a Dios y a las inteligencias, es el objeto adecuado de esta ciencia. Opinión que suele atribuirse al Comentador en el libro I de la Física, comentario último. Pero allí sólo dice que las inteligencias por sí mismas pertenecen al objeto de esta ciencia, y no que sean el objeto adecuado. ${ }^{17}$

Según la letra de la objeción, hay aquí un doble inconveniente respecto de la supuesta posición especulativa de Averroes. Si atendemos a Suárez, la interpretación de la época (i) sobre los textos de Ibn Rushd sostendría que el objeto adecuado de la ciencia metafísica es la sustancia o ente inmaterial.

dogmático obviando las otras posiciones especulativas. Era necesario poner en evidencia sus falencias y mostrar el auténtico camino de la filosofía metafísica. Tal escenario esclarece, a su modo, la razón por la que las Disputationes no son un comentario al tratado aristotélico de la metafísica según la costumbre medieval precedente, sino un tratamiento exhaustivo de temas y tópicos que tal obra presenta.

${ }^{16}$ En razón de los intereses enunciados, el presente estudio persigue el propio cuestionamiento de Francisco Suárez, postergando para el futuro artículos que contrasten la posición especulativa del Dr. Eximio con los casos de Averroes y Aristóteles. Se busca destacar la reflexión suareciana que antecede de modo directo al libro segundo de las D.M. donde se presenta la comprensión del concepto de ente formal y objetivo.

${ }^{17}$ F. Suárez, D.M. I, I, 14: "Quarta ergo opinio sit substantiam aut ens immateriale, prout in se includit solum Deum et intelligentias, esse adaequatum obiectum huius scientiae. Quae opinio solet tribui Commentatori, I Phys., comm. ultimo. Sed ibi solum dicit intelligentias per se pertinere ad obiectum huius scientiae, non vero esse adaequatum obiectum”. 
La sinonimia entre ambos términos expresa la superioridad de la ciencia metafísica respecto de la física. Mientras que ésta se ocupa de la sustancia material, aquella lo hace de la inmaterial. La sustancia en sí, ajena a la cantidad, el tiempo, el lugar y las demás categorías de índole física, carece de materia. Esta negación de lo primero ante los sentidos - la materia del ente- coloca la sustancia inmaterial al modo de última quoad nos. De allí que el ente metafísico contenga a Dios y a las inteligencias, y que todo ello sea superior al universo físico y creado.

Ahora bien, el matiz de la objeción está dado en la noción de objeto adecuado. La tesis dice que el ente inmaterial es el objeto adecuado de la metafísica, y su contenido es Dios y las inteligencias. Hay aquí cierta lógica que no puede soslayarse. La noción de objeto adecuado antecede a su contenido. Debe darse ante la mente la comprensión de aquello que sea objeto y adecuado antes que Dios y las inteligencias. Esto es, no hay duda, según reza la objeción, de la existencia de Dios y de las sustancias intelectuales, sino de que ellas sean el objeto adecuado propio y total de la metafísica. Esta es la primera deducción de la tesis y el primer inconveniente. Consecuentemente con ello, queda esclarecido que el contenido de la metafísica es tal porque hay un objeto adecuado que muestra la dependiente vinculación de dicho saber con la inteligencia humana.

La noción de objeto es relacional. Establece un enlace entre la inteligencia humana y los entes reales inmateriales. Pero dicha relación halla fundamento en la persona humana antes que en Dios o las inteligencias. Y por esta razón el contenido de la ciencia metafísica señala un ámbito de lo real mediado, propiciado y antecedido por un proceder lógico y gnoseológico. En efecto, si la sustancia metafísica es en definitiva el ente inmaterial, y ella hace las veces de objeto adecuado, se sigue necesariamente que el objeto adecuado se dice primero y con propiedad ente inmaterial y no Dios y las inteligencias. Y ello es conforme con la exploración de Suárez sobre la cientificidad de la metafísica según lo muestran las objeciones que principian las D.M. I, I y de la cual esta objeción es parte.

Asimismo, la objeción presenta un segundo nivel de interpretación. Si la tesis ha afirmado que el objeto adecuado de la metafísica es el ente inmaterial, ahora deberá mostrar que el ente inmaterial se interpreta correctamente como Dios y las inteligencias. Y allí se precisa una restricción: sólo o únicamente Dios y las inteligencias. Pues éste es el objeto adecuado de la ciencia máxima. La noción lógica de incluir (includo) y la restricción señalada hacen de la objeción una formulación gnoseológica que supone un descenso lógico desde el ente inmaterial hacia lo real. El ente inmaterial 
coloca bajo sí lo real inmaterial —Dios y las inteligencias-; y lo hace en términos abstractos, pues lo común entre Dios y las inteligencias es lo inmaterial. En efecto, la distancia infinita entre la creación angelical y el Creador hace suponer que la común consideración de ambos en una ciencia sea en términos lógicos donde lo real queda asumido por efecto de la operación abstractiva del intelecto.

El objeto adecuado de la ciencia metafísica es objetivo. Suárez presenta la presunta objeción del filósofo cordobés según su propia reformulación. La doctrina metafísica pone de manifiesto una hermenéutica no exclusivamente lógica ni real, sino ambas a la vez. Dios y las inteligencias son entes inmateriales reales. Por ello el objeto adecuado de la metafísica expresa un saber de lo real. Sin embargo, si bien la estructura de la objeción nos conduce únicamente y de modo descendente desde la sustancia y el ente inmaterial hacia Dios y las inteligencias, la noción de inclusión permite entrever cierto margen o amplitud. En efecto, la segunda anotación del Granadino repara en la diferencia entre la noción de 'objeto' y 'objeto adecuado'. Toda la objeción, ahora sí, debería comprenderse como objeto (ii), según el siguiente texto: "pero allí sólo dice que las inteligencias por sí mismas pertenecen al objeto de esta ciencia, y no que sean el objeto adecuado."

La afirmación supra no es vana y vuelve sobre la tesis central de acuerdo con algunos matices diferenciantes. Si lo común a Dios y las inteligencias es la inmaterialidad, queda presente la ambigüedad de Dios como objeto u objeto adecuado. El hecho de desplazar las inteligencias desde la estructura de objeto adecuado hacia aquella de objeto puede entenderse en relación con Dios y los ángeles, o únicamente en relación con los ángeles, puesto que la noción de inteligencia es común a ambos seres inmateriales a pesar del pondus metafísico en cada caso. A la vez y sobre la ambigüedad presente, la corrección a la interpretación sobre la Física de Averroes colabora en su propia comprensión sobre el saber científico. Aquí se coloca nuevamente la noción de objeto adecuado como epicentro de la doctrina de las ciencias. De acuerdo con ello, al ser Dios y las inteligencias el contenido exclusivo de la metafísica, ahora ese contenido, que dice la noción de ente inmaterial, es re-significado. Ciertamente son objetos de la metafísica, pero no el objeto adecuado. Esto es, la ciencia metafísica trata acerca del ente inmaterial, que es su objeto adecuado, y su contenido (a) no parece incluir a la vez con necesidad a Dios y las inteligencias, y (b) incluye con necesidad únicamente a Dios, desplazando a las inteligencias hacia el contenido de simple objeto. Por esta razón el ente inmaterial es adecuado como objeto al señalar con precisión un único objeto de especulación: Dios. La primacía de Dios 
respecto de los ángeles se fija así como segunda tesis subsidiaria de la primera y formulada como rectificación de la filosofía de Averroes. El argumento que la defiende es útil para ambas tesis. La fundamentación siguiente ilustraría un cierto modo medieval en el que se interpreta al Filósofo - en alusión a Ibn Rushd- al comprenderse, a la vez, la relación entre la naturaleza en su totalidad y la ciencia que la explica. Veamos ello con mayor detalle.

Puede esta opinión fijarse en el desarrollo o división de las ciencias, pues omitidas las ciencias racionales, que más bien son como artes y se ocupan de las voces o de los conceptos, y las ciencias matemáticas, que no tratan de la sustancia, sino de la sola cantidad, entre las ciencias que se ocupan de la sustancia $\left[\ldots . .{ }^{18}\right.$

Si el objeto adecuado constituye el epicentro por el que una disciplina es ciencia, entonces desplazar a los ángeles hacia la simple noción de objeto significa que Dios cumple mejor los requisitos de objeto adecuado. Empero, la razón por la que Dios y las inteligencias han sido considerados como objeto adecuado estaría plenamente arraigada —en lenguaje de Suárez- en la interpretación aristotélica de las ciencias ofrecida por la tesis primera, aun cuando la tesis segunda haya señalado cierta divergencia.

Ahora bien, el supuesto general que subyace a la objeción alude a las ciencias especulativas cual marco de comprensión más amplio que la misma ciencia metafísica. Lo que ellas tienen en común son su inutilidad para la práctica y su consideración teorética de los entes. Y esta es una diferencia que debe ser subrayada. Las ciencias especulativas parecen señalar dicha común denominación antes que el hecho de que traten acerca de las sustancias, puesto que no todas las ciencias las consideran. Por un lado la lógica y la matemática; por el otro, aquellas que tienen en común la noción de sustancias. De modo que, según se deduce, la armonía de los cuatro saberes especulativos es abstracta.

entre las ciencias que se ocupan de la sustancia, la filosofía trata de todas las sustancias generables y corruptibles, y de las sustancias incorruptibles, y de la sustancia compuesta de materia y forma inmaterial, como es el hombre, y de la misma forma inmaterial, es decir, del alma racional, y finalmente de los cinco grados u órdenes de sustancias materiales, a saber: de los cuerpos simples, de los compuestos inanimados, de los compuestos con sola vida vegetativa, con sola vida sensitiva, y con vida racional, y de todas sus propiedades. Nada queda, pues, por estudiar en la realidad (in rebus), excepto las sustancias inmateriales; ellas son, pues, las que cubren el objeto adecuado de esta ciencia. ${ }^{19}$

${ }^{18}$ F. Suárez, D.M. I, I, 14: "Potest autem haec opinio suaderi ex discursu seu partitione scientiarum; omissis enim scientiis rationalibus, quae potius sunt artes quaedam et de vocibus seu conceptibus tractant, et scientiis mathematicis, quae non agunt de substantia sed de sola quantitate, inter scientias quae agunt de substantiis [...]".

${ }^{19}$ F. Suárez, D.M. I, I, 14: “inter scientias quae agunt de substantiis philosophia tractat de omnibus substantiis generabilibus et corruptibilibus, et de substantiis etiam corporeis 
Una lectura completa de la descripción ofrecida por el Dr. Eximio respecto de la fundamentación de la objeción exhibe el quehacer de las ciencias físicas y metafísicas. Estas son las dos ciencias especulativas que tratan acerca de las sustancias. A su vez la primera de ellas presenta una serie de estratos que manifiesta una gradación interna de saberes. La física trata sobre las sustancias generables y corruptibles, lo que indica la totalidad del mundo sublunar. También versa acerca de las sustancias incorruptibles o mundo supra lunar. En un orden descendente hallamos primero la física de los astros o ciencia de la astronomía cuyo objeto adecuado son las sustancias incorruptibles. Luego la física de los seres biológicos, que es sobre las sustancias compuestas y corruptibles en su totalidad. De acuerdo con ello encontramos primero la antropología o ciencia acerca de la materia (cuerpo) y forma inmaterial (alma racional) o bien de la misma forma inmaterial, cuyo sentido versaría acerca de la existencia del alma en sí misma separada del cuerpo. ${ }^{20}$ Después de la antropología la descripción es ascendente. En primera instancia, los cuerpos simples o elementos - v.g. aire, fuego, tierra y agua- y luego los compuestos inanimados o minerales. A su vez, sobre la física de los elementos y compuestos simples, están los compuestos animados, cuyos estratos son tres. Continuando con un orden ascendente, primero hallamos la vida vegetal y sus propiedades — vida ausente de movimiento traslaticio y de sensibilidad-, y posteriormente la vida sensitiva que incorpora el sentir y el movimiento traslaticio, cual es el caso de la totalidad del reino animal superior. En tercera instancia, la vida humana sobre la que se ha expuesto sus rudimentos. De donde, de modo descendente, la física se divide en: 1. Astronomía; 2. Biología: 2.1. Antropología; 2.2. Zoología; 2.3. Botánica; 3. Mineralogía; 4. Sobre los elementos simples.

Según la presente división de saberes, la física no tiene como objeto adecuado las sustancias inmateriales. Por lo tanto la filosofía ubica en la ciencia de la metafísica aquellas sustancias de Dios y las inteligencias como objeto adecuado. Y lo hace de modo exclusivo, porque cualquier otra sustancia es tema de estudio de alguna de las ciencias físicas.

incorruptibilibus, et de substantia etiam composita ex materia, et immateriali forma, qualis est homo, et de ipsa etiam forma immateriali, anima scilicet rationali, ac denique de quinque gradibus seu ordinibus materialium substantiarum, scilicet simplicium corporum, mixtorum inanimatorum, vegetabilium tantum, sentientium tantum, et rationalium, et de omnibus proprietatibus eorum. Nihil ergo sciendum superest in rebus praeter immateriales substantias; illae ergo complent obiectum adaequatum huius scientiae".

${ }^{20}$ J. B. South, "Some Themes in Suárez's Account of the Separated Soul”, Pensamiento 74/279 (2018), 63-74. 


\section{Una fundamentación aristotélica inadecuada sobre la división de las ciencias}

Suárez no está interesado en refutar al filósofo Andalucí. La objeción es una excusa para corregir una interpretación de los textos del Estagirita propia de la época que bien pudo valerse de Averroes para justificarse a sí misma. Ahora bien, la supuesta lectura averroísta de las ciencias haría foco en ciertos pasajes de la metafísica de Aristóteles con los que el Dr. Eximio no estaría del todo de acuerdo. Por consiguiente, la argumentación que justifica la credibilidad de la división de las ciencias antes expuesta colocaría todo este saber en un ámbito no conjetural ni plausible, ya porque efectivamente parece haberse sostenido en tiempos del Granadino, ya porque también mantiene en sí misma cierto rigor especulativo.

El esquema de la argumentación es doble. En primer lugar (i) la división de las ciencias especulativas tiene sede en las citas de autoridad: el caso de Aristóteles. En cambio, en segundo lugar (ii), la autoridad aparece difusa bajo la expresión "comúnmente se distingue."

Todo este razonamiento puede confirmarse en primer lugar con un doble testimonio de Aristóteles. Uno será en el libro IV de la Metafísica, texto 4, donde dice que son tantas las partes de la filosofía cuantas son las sustancias, por lo cual, siendo dos las clases de sustancias, material e inmaterial, así dos son las ciencias que filosofan acerca de las sustancias. De donde concluye que aquella es la filosofía primera por cuanto trata acerca de la sustancia primera, esto es, en cuanto contempla la sustancia inmaterial. $^{21}$

Si la división de las ciencias ha sido explicada según el presunto sentir de Averroes es porque su lectura parece plausible respecto de la Metafísica de Aristóteles. Y es allí a donde Suárez le interesa llegar. Mediado por la filosofía musulmana, el foco de atención está puesto en la filosofía griega cuya exégesis debe ser otra. Ciertamente el texto aristotélico fue leído al modo de Ibn Rushd, y ésta es la razón que aparece formulada como tesis en la objeción. Luego el despliegue de la totalidad del saber filosófico real y especulativo encuentra asidero en las sustancias que conforman y están presentes en el universo. Por ello la filosofía aristotélica se divide según las sustancias. Y como son de dos clases, se sigue que la filosofía especulativa

${ }^{21}$ F. Suárez, D.M. I, I, 14: "Qui totus discursus primo confirmari potest duplici testimonio Aristotelis. Unum est IV Metaph., text. 4, ubi dicit tot esse partes philosophiae quot substantiae. Unde, sicut duplex est substantia, materialis scilicet et immaterialis, ita duplex est scientia quae de substantiis philosophatur; unde concludit illam esse primam philosophiam quae primam substantiam, id est, immaterialem contemplatur". 
se divida en dos. Las sustancias materiales propias de la física, cuya división ya fue explicitada, y las sustancias inmateriales que son el objeto contemplativo de la metafísica.

Hay en el texto un detalle más. No sólo se explicita la división sino también su jerarquía. En el ámbito de los estratos naturales, que hacen de fundamento de las ciencias que las estudian, lo material es inferior a lo inmaterial. Por consiguiente, en el ámbito de las ciencias, por correlación con lo natural, la física es inferior a la metafísica. Ahora bien, esta es una cuestión que únicamente encontrará sustento en el segundo argumento.

El segundo testimonio está en el libro VI de la Metafísica, texto 3, donde afirma Aristóteles que si no existiesen sustancias que abstraigan de la materia según el ser, la filosofía natural sería la primera y no habría otra ciencia necesaria fuera de ella. Luego, toda la razón objetiva de esta ciencia, que la constituye a su modo y la distingue de las demás, es la sustancia inmaterial. Por tanto este es su objeto adecuado.22

La filosofía primera o metafísica es superior a la física en razón de la consideración de sus objetos, que son naturales, inmateriales y superiores a la materia. El primer testimonio de Aristóteles a favor de dicha tesis afirmaba la inferioridad de la física en comparación con la metafísica. Y el segundo testimonio es su fundamento. Ahora bien, de acuerdo con el texto, la razón de esta jerarquía pivota sobre dos cuestiones. En primer lugar la filosofía natural podría ser llamada también filosofía primera si no hubieran sustancias que abstraigan de la materia según el ser. En correlación con ello, el objeto adecuado de la física proviene de la abstracción racional de la materia en orden a considerar el singular material de modo universal. Y como esta ciencia abarca la totalidad de entes sensibles según sus niveles y complejidades, se sigue que podría ser considerada la ciencia máxima. En segundo lugar está la afirmación indubitable de la existencia de sustancias inmateriales y superiores, cuya constitución escapa al ámbito de la física. Eh allí el sustrato de la metafísica. Aquello cuyo objeto no se adecúa a la ciencia natural.

El objeto de las consideraciones metafísicas es la sustancia o ente inmaterial. La explicación de lo que ello significa proviene de la noción de abstracción. En efecto, ente inmaterial significa "sustancia que abstrae de la materia según el ser." Y esta definición refleja el nombre de la ciencia

${ }^{22}$ F. Suárez, D.M. I, I, 14: “Alterum testimonium est VI Metaph., text. 3, ubi Aristoteles ait, si non essent substantiae secundum esse abstrahentes a materia, naturalem philosophiam fore primam, neque praeter illam fore aliam scientiam necessariam; ergo tota ratio obiectiva huius scientiae, quae illam suo modo constituit et ab aliis distinguit, est substantia immaterialis; haec ergo est adaequatum obiectum eius". 
en cuestión. La metafísica es la ciencia que está más allá de la física. Y consiguientemente, es aquel saber que abstrae de la consideración física. Por ello se afirma que su objeto abstrae de la materia según el ser. Aquí abstraer significa separación y alejamiento bajo el siguiente respecto. Si el ente de las sustancias de la física es material, entonces separarse de la materia según el ser no es despojarse de la materia ya dada en el ente, sino señalar aquellas sustancias cuyo ser no conlleva materialidad. Luego, si en la naturaleza existe el ente inmaterial según la presente definición, el ámbito que la considera como objeto adecuado únicamente puede ser metafísico. Por esta afirmación el conocimiento metafísico es también objetivo, puesto que señala la consideración de la razón respecto de los entes inmateriales reales. Y conviene añadir que una cuestión ha sido mostrar la existencia de la ciencia metafísica según su objetividad en tanto trata acerca de los entes inmateriales, y otra cuestión es el modo en que el ser humano aprehende ese saber de lo inmaterial. En orden a señalar este aspecto subrayamos la noción de objeto, porque para la razón humana abstraer sí significa alejarse de los entes materiales, no porque los despoje —según ya se afirmó- sino porque debe ingresar - mediante la negación de la materialidad y la focalización en lo inmaterial - en el ámbito de lo que de suyo carece de materia.

En segundo lugar se confirma esta opinión porque comúnmente se distingue la filosofía natural, la matemática y la metafísica por la abstracción de sus objetos, ya que la física estudia las cosas que constan de materia sensible; la matemática abstrae de aquella materia según la razón y no según el ser, y por eso se dice que no abstrae de la materia inteligible; y la metafísica, en cambio, abstrae tanto de la materia sensible como inteligible no sólo según la razón sino también según el ser. Y como solo la sustancia inmaterial abstrae de la materia según el ser, es ella el objeto adecuado de esta ciencia. ${ }^{23}$

Se había señalado que la opinión averroísta sobre el objeto adecuado de la metafísica tenía detrás una interpretación de raíz aristotélica sobre la división de las ciencias. El primer argumento era a su vez doble y presentaba, a modo de basamento, la autoridad de Aristóteles. Ahora Suárez coloca el segundo argumento bajo una autoridad ciertamente anónima o difusa de acuerdo con la expresión "comúnmente se distingue." Presumiblemente,

${ }^{23}$ F. Suárez, D.M. I, I, 14: "Secundo confirmatur, quia communiter distinguuntur philosophia naturalis, mathematica et metaphysica, ex abstractione obiectorum; nam physica considerat res materia sensibili constantes; mathematica abstrahit ab illa materia secundum rationem, non autem secundum esse, et ideo dicitur non abstrahere a materia intelligibili; metaphysica vero abstrahit a materia tam sensibili quam ab intelligibili, non solum secundum rationem, sed etiam secundum esse; sed sola substantia immaterialis abstrahit a materia secundum esse; ergo illa est obiectum adaequatum huius scientiae”. 
según su propia formación en la tradición científica aristotelizante, tal expresión señale, en concordancia con la objeción, las posiciones de Tomás de Aquino y Tomás de Vío Cayetano entre otros.

Las ciencias especulativas son cuatro: lógica, matemática, física y metafísica. Las dos primeras habían quedado apartadas por no tratar acerca de la sustancia. Las dos siguientes son el objeto de estudio en el caso puntual de la objeción. Aquí se consideran tres de ellas, porque la división tradicional aristotélica sobre las ciencias especulativas es tripartita. Separando la lógica, la matemática comparte con la física y la metafísica el procedimiento abstractivo en orden a sus objetos adecuados.

El proceso abstractivo difiere, en cada caso, según el objeto a considerar. Y el objeto es tal para la mente humana cuando se ha operado abstractivamente. De allí el círculo cognoscitivo cual fundamento de la división de las ciencias. La ciencia primera quoad nos es la física. Y según esto, habíase afirmado que su objeto adecuado proviene de la abstracción racional de la materia en orden a considerar el singular material de modo universal. Y ahora se añade lo siguiente: la física "considera las cosas que constan de materia sensible." Ambas definiciones señalan lo mismo. Si lo apuntado hasta aquí tiene cual modus rationlis la operación de la abstracción, y con ello se alcanza su consideración propia, que es su objeto adecuado, se sigue que ese objeto adecuado son las sustancias de materia sensible, y ello de modo universal, puesto que dicha nota destaca la física como ciencia. Ahora bien, esta es la primera abstracción, porque el ser humano comienza conociendo por los sentidos. De allí el primer universal: la materia sensible y no inteligible.

La ciencia matemática se alcanza por abstracción de la materia sensible. De allí el segundo universal: la materia inteligible y no sensible. En efecto, si la matemática abstrae según la razón es porque la operación racional comienza en la materia sensible —ámbito de la física- para concluir en sí misma cual matemática, esto es, la materia inteligible. Por ello se enuncia como abstracción según la razón y no según el ser. Ocuparse de la abstracción según el ser es, según ya se dijo anticipadamente, señalar el ente inmaterial, que es el objeto adecuado de la metafísica. Por su parte este último saber especulativo, alcanzado también para el hombre por abstracción, señala el tercer grado de universalidad: el ente o la sustancia inmaterial. Si antes la razón abstraía del ente la singularidad en cuanto singularidad para abocarse a la materia sensible, y luego abstraía la materia inteligible, ahora abstrae de ambas materias. No hay allí materia sensible ni inteligible. Solo el ente inmaterial. Y como ello no puede ser simplemente una proyección 
ilusoria, se ha resaltado que este movimiento de la razón está basado en la previa certeza de la existencia de tales entes: Dios y las inteligencias. De ahí que el argumento culmine con la noción de objeto adecuado para el ente inmaterial, y que esta noción diga de suyo a Dios y los ángeles.

\section{El criterio de Suárez sobre la metafísica y la división de las ciencias espe- culativas}

El desarrollo de la objeción ha incluido una presentación de las ciencias especulativas, su orden y sus definiciones. Hay en ello un supuesto: la búsqueda de una correcta comprensión del objeto adecuado de la metafísica supone consecuencias insoslayables para la totalidad de la doctrina de las ciencias. Por esta razón era necesario esclarecer y fijar adecuadamente el objeto metafísico, ya por su gobierno directriz sobre las demás ciencias, ya por la necesidad de precisar su ámbito científico propio.

Pero esta opinión, como he dicho, no tiene mayor probabilidad que la precedente, y de allí que no haya ningún autor serio que la defienda, ya que todo el razonamiento expuesto procede con criterio poco amplio. Acertadamente prueba el argumento que las sustancias inmateriales pertenecen máximamente al objeto de esta ciencia. Prueba también que de las cosas que existen en la naturaleza, ninguna otra cae por sí y por sus propias razones bajo el objeto de esta ciencia más que las sustancias inmateriales, como diremos contra Egidio poco después. ${ }^{24}$

La cuarta tesis que malinterpreta el objeto adecuado de la metafísica sostenía: "la sustancia o ente inmaterial incluye sólo a Dios y a las inteligencias." La tesis precedente a su vez rezaba: "el ente supremo real, que es Dios, es el objeto adecuado de la metafísica." 25 Ambas objeciones son completamente insostenibles, no porque la metafísica desconsidere a Dios y a los ángeles, sino porque en tales casos el criterio es poco amplio. Dios y las inteligencias están incluidos en el objeto de la metafísica. Pero no al modo en que la objeción los presenta, y ciertamente no como los interpreta Egidio Romano. De allí la necesidad de esclarecer el modo propicio en el que deben ser considerados.

${ }^{24}$ F. Suárez, D.M. I, I, 15: "Haec vero sententia, ut dixi, non habet maiorem probabilitatem quam praecedens; unde nullus est gravis auctor qui illam defendat, nam in toto discursu facto diminute procedit. Probat quidem recte ille discursus substantias immateriales maxime pertinere ad obiectum huius scientiae. Probat etiam ex rebus subsistentibus in rerum natura nullas alias cadere per se et secundum proprias rationes sub obiectum huius scientiae praeter substantias immateriales, ut paulo inferius contra Aegidium dicemus".

${ }^{25}$ F. Suárez, D.M. I, I, 8: “Tertia itaque opinio, et per extremum opposita, solum supremum ens reale (Deum videlicet) facit obiectum huius scientiae adaequatum”. 
A juicio de la respuesta el acento está colocado en la noción "sólo, únicamente, con exclusividad." No es posible que Dios y las inteligencias sean solamente el objeto adecuado de la metafísica. Dice Suárez que ese criterio es ciertamente estrecho, al argumentar, símil a la objeción, con idéntico criterio: la tradición medieval. La respuesta suareciana la incorpora con el fin de salvaguardar a aquellos teólogos y filósofos medievales por él estimados, y de los cuales parece declararse continuador. De allí que su corrección supone también poner de manifiesto que su pensar no contraría la doctrina metafísica aristotelizante fundamental de la Edad Media, encubriéndose así la novedad especulativa de su filosofía, tanto para la contemporaneidad como para su presente.

Sobre la base de esta retórica metafísica el Dr. Eximio se apresura a matizar algunas de las cuestiones traídas a colación en la objeción. Hay aquí una apropiación de verdades comunes que hacen ahora de fundamento para el argumento suareciano. Y estas verdades son dos: 1. las sustancias inmateriales - v.g. Dios y las inteligencias- pertenecen máximamente al objeto de la ciencia metafísica; 2. las mismas sustancias inmateriales caen por sí y por su propias razones bajo el objeto de la metafísica. En ninguno de los dos casos Suárez escribe objeto adecuado o único objeto adecuado. Por consiguiente, afirmar que Dios y las inteligencias máximamente pertenecen de suyo, sin externas razones, al objeto de la metafísica es decididamente diferente a asignarles su perfecta adecuación. En ello, la segunda verdad asume rectamente las divisiones y objetos adecuados de la ciencia física cuando dice: "las cosas que existen en la naturaleza."

Pero no prueba ni concluye rectamente que la sustancia inmaterial como tal sea el objeto adecuado de esta ciencia, ya que en la misma sustancia inmaterial pueden considerarse otras razones o conceptos objetivos más universales y comunes, acerca de los cuales, según su razón adecuada, puede darse alguna ciencia, puesto que a tales razones corresponden sus propios principios y propiedades. ${ }^{26}$

El defecto interpretativo, en la división de las ciencias antes ilustrada, estaba en la equívoca deducción respecto del objeto de la metafísica. De allí la postulación de la objeción y la necesidad de argumentarla mostrando aquella división señalada. El origen de dicho error estaba en la interpretación de los estratos naturales. Si a cada nivel de la naturaleza - v.g. elementos,

\footnotetext{
${ }^{26}$ F. Suárez, D.M. I, I, 15: "Non tamen probat nec recte concludit, substantiam immaterialem ut sic esse obiectum adaequatum huius scientiae, quia in ipsa immateriali substantia considerari possunt aliae rationes seu conceptus obiectivi universaliores et communiores, de quibus secundum adaequatam rationem potest aliqua scientia tradi, nam his rationibus respondent propria principia et proprietates".
} 
minerales, plantas - le corresponde una ciencia - v.g. ciencia de los elementos, ciencia de los minerales y botánica-, entonces la realidad de Dios y de los ángeles, al estar fuera del ámbito de la ciencia genérica de la física, debía ser objeto de otra. Así razonados los estratos de la naturaleza, aquella ciencia, que tiene por único objeto adecuado a tales entes, es la metafísica.

La advertencia del Granadino ya fue enunciada y la fuerza de sus palabras parecería venir de la escolástica medieval. Contra aquel modo de razonar postula su propia tesis resolutiva: el objeto adecuado de la ciencia metafísica no es el ente inmaterial o la sustancia inmaterial. En efecto, siendo el ente inmaterial objeto de la ciencia metafísica, también él lleva en sí otras razones o conceptos objetivos más universales y comunes que Dios y los ángeles. Por esta razón, tales conceptos objetivos, efectivamente superiores al ente inmaterial donde queda incluido Dios y las inteligencias, se constituye, según su razón adecuada, en tema de alguna ciencia. Y esa ciencia es la misma metafísica que incluye al ente inmaterial y lo que este concepto indique. No hay otra metafísica; no hay varias metafísicas. Los temas metafísicos no señalan que existan varias ciencias. Ahora bien, la noción de sustancia inmaterial conlleva en sí conceptos objetivos adecuados — según sus propios principios y propiedades - y los pone de manifiesto en el tratamiento de la metafísica. Por lo tanto, el objeto adecuado de la metafísica son los conceptos objetivos de suyo más universales que la noción de sustancia inmaterial que dependen, a su vez, de la unidad objetiva del concepto de ente. ${ }^{27}$ Con esta afirmación Suárez arroja completamente por tierra la objeción de marras. Toda la formulación de la objeción está errada en su enfoque. No es el ente inmaterial, ni Dios, ni las inteligencias el objeto adecuado de la ciencia metafísica. Nuevamente, destaca el Dr. Eximio, el objeto adecuado de la metafísica es, en definitiva, el concepto de ente en cuanto ente. ${ }^{28} \mathrm{Y}$ de esta noción dependen los conceptos objetivos aquí desentrañados emergentes de la noción de sustancia inmaterial.

${ }^{27}$ F. Suárez, D.M. I, 1, 6; F. Suárez, D.M. I, 1, 26: "nam illa revera sunt entia et sub unitate conceptus obiectivi entis aliquo modo comprehenduntur."; "Dicendum est ergo, ens in quantum ens reale esse objectum adaequatum hujus scientiae".

${ }^{28}$ R. Darge, "Suárez on the Subject of Metaphysics", en V. Salas and R. L. Fastiggi (eds.), A Companion to Francisco Suárez, Leiden, Brill, 2014, p. 93: Véase también una breve historia de la noción de subiectum metafísico y las diferentes opiniones que se suscitan sobre la interpretación suareciana, pp. 91-96. Del estudio citado se deduce que el espectro de interpretaciones sobre el subiectum metafísico no tiene en consideración la génesis o emergencia del concepto de ente en cuanto ente, tema sobre el cual brevemente nos hemos explayado. Únicamente su comprensión en términos objetivos y conceptuales, que es lo consensuado entre las diferentes variantes, y que constituye, a la vez, la línea hermenéutica seguida. 
Pues ninguna otra ciencia, además de la metafísica, contempla estas razones. Por ello el objeto adecuado de la metafísica ha de ser señalado desde alguna razón más universal. Por lo tanto, aunque concedamos el discurso e inducción referidos a todas las cosas materiales según aquellas razones en las que no convienen con las inmateriales, se sabe con suficiencia, por medio de las otras ciencias distintas de la metafísica, que no se concluye rectamente que la sustancia inmaterial como tal sea el objeto adecuado de esta ciencia, pues todavía quedan razones comunes a unas y otras cosas o sustancias comunes en las que pueden llevarse a cabo sus propias demostraciones. ${ }^{29}$

\section{A modo de conclusión}

La búsqueda del objeto de la metafísica se precisa en Suárez como objeto adecuado. El Dr. Eximio no persigue una comprensión de la metafísica en términos de objeto principal (v.g. Dios) y los subsiguientes objetos secundarios (v.g. los trascendentales verum, bonum, unum, res, aliquid)..$^{30}$ Lejos de esta visión, las respuestas a las objeciones precedentes y consiguientes fijan la noción de objeto adecuado como aquel sustrato y fin sobre el que una ciencia versa. El objeto adecuado de la ciencia de la sabiduría es, a juicio de la respuesta definitiva a la cuarta objeción, los conceptos objetivos emergentes de la noción de sustancia o ente inmaterial. Y por ello, deductivamente, la metafísica trata acerca del ente inmaterial, de Dios y de las inteligencias. Cada uno de ellos es objeto de la metafísica, pero no el objeto adecuado.

A diferencia de las metafísicas escolásticas, donde el subiectum de la ciencia de la sabiduría es el ente en cuanto ente, en Suárez se evidencia - a pesar de su esfuerzo por ocultar la novedad especulativa en cuestiónuna modificación en la terminología y el surgimiento de un nuevo ámbito por donde discurre la ciencia en general, y la metafísica en particular: la gnoseología de la objetividad. ${ }^{31}$ De acuerdo con ello la lectura de la tradición aristotelizante escolástica de la Edad Media aparece empastada con

${ }^{29}$ F. Suárez, D.M. I, I, 15: "nulla autem alia scientia praeter metaphysicam has rationes contemplatur; igitur adaequatum metaphysicae obiectum sub aliqua universaliori ratione designandum est. Quamvis ergo discursui et inductioni factae concedamus omnes res materiales, secundum eas rationes in quibus cum immaterialibus non conveniunt, sufficienter sciri per alias scientias a metaphysica distinctas, non recte concluditur immaterialem substantiam ut sic esse obiectum huius scientiae adaequatum, quia adhuc supersunt rationes utrisque rebus seu substantiis communes, in quibus propriae demonstrationes fieri possunt”.

${ }^{30}$ L. Prieto López, "Res, aliquid y nihil en Suárez y la filosofía moderna", Anales del seminario de historia de la filosofía 30/1 (2013), 49-69.

${ }^{31}$ Cfr. J.M.F. Mendoza, "Un ítem central en la doctrina científica de Francisco Suárez: del subiectum al obiectum como sustrato de cada ciencia especulativa", Rivista di Filosofia Neo-Scolastica CXI/3 (2019), 607-623. 
ese vocabulario: objeto adecuado, concepto objetivo, abstracción y ente inmaterial son algunas de las nociones claves. Y en concordancia con ello, la metafísica no podrá definirse como el estudio del ente en cuanto ente más que en clave conceptual. ${ }^{32}$

Según la objeción hay identidad esencial entre sustancia inmaterial y ente inmaterial. Tal ente aparece como objeto adecuado de la metafísica y dice incluir a Dios y a las sustancias intelectuales. De donde, según el Granadino, conviene reparar en aquella hermenéutica fundamental: 1. objeto adecuado, 2. sustancia o ente inmaterial, 3. Dios / Dios y los ángeles. Este es el camino lógico de la objeción metafísica que le interesa a Suárez, y es la razón por la que Averroes - presunto exponente de la objeción allí formulada- es desconsiderado. Junto con ello, la mediación entre la objeción y la respuesta definitiva está configurada según la posición especulativa de Aristóteles. La lectura presuntamente averroísta sobre las ciencias según el parecer del Estagirita no es, de acuerdo con el Granadino, del todo equívoca. Efectivamente hay una apropiación del Dr. Eximio — si bien en sede objetiva- de la división de las ciencias. Suárez acepta el esquema fundamental de raíz aristotélica configurado según su entender: 1. la totalidad de la doctrina científica es leída en sede objetiva y conceptual; 2 . el sujeto de cada ciencia es la noción de objeto adecuado; 3 . los objetos adecuados de las ciencias especulativas son conceptos objetivos; 4 . los objetos adecuados son alcanzados por abstracción; 5. las ciencias especulativas se jerarquizan según el grado de abstracción o universalidad: 5.1. Física, 5.2. Matemática, 5.3. Metafísica.

Ahora bien, sobre estos pilares que manifiestan la arquitectura de la ciencia, aquel camino lógico señalado supra y conducente desde el objeto adecuado hacia Dios, es reconsiderado por Suárez a partir de una serie de principios superiores en conjunto con sus propiedades. A su vez ello es consecuencia de la contemplación del objeto metafísico ente inmaterial. En efecto, lo que allí opera es la lógica de la inducción de los principios configurantes del ente inmaterial de suyo más universales y comunes. Y entre estos principios el primero es el concepto objetivo de ente en cuanto ente. Por esta razón la totalidad del texto presenta dos ejes: 1. el desplazamiento del ente inmaterial desde objeto adecuado a objeto; 2 . la colocación y el entendimiento de esos principios emergentes del ente inmaterial como auténtico objeto adecuado de la metafísica, y que en última instancia, según

\footnotetext{
${ }^{32}$ R. Darge, "Suárez on the Subject of Metaphysics", en V. Salas and R. L. Fastiggi (eds.), A Companion to Francisco Suárez, Leiden, Brill, 2014, p. 116.
} 
aquí se ha afirmado, está todo ello centralizado en el concepto de ente en cuanto ente. Por esta causa el orden deductivo correcto es el siguiente: 1 . objeto adecuado: conceptus obiectivi entis; 2 . desde y en el objeto adecuado: los principios comunes y universales objetivos; 3 . objeto: ente inmaterial; 4. Dios y las inteligencias. Empero este ordenamiento no entorpece la orientación definitivamente teológica de la ciencia metafísica, puesto que, al decir de Suárez, una sólida fundamentación de la filosofía primera permite colocar los adecuados cimientos para el despliegue de la teología sagrada. ${ }^{33}$

\section{Bibliografía}

Alejo Montes, F. J., "La Universidad de Salamanca en el s. XVI: la reforma educativa de D. Juan de Zuñiga (1594)", Studia histórica: Historia Moderna 8 (2009), pp. 151-162.

Bonino, S.-T., “Avant-propos. Le thomisme et son historie”, R.T. 97 (1997), pp. 5-8.

Bonino, S.-T., "L'école thomiste au XVe siècle”, RTLu V/2 (2000), pp. 223-234.

Bonino, S.-T., "Le thomisme parisiena u XVe siècle", R.T. 107 (2007), pp. 625-653.

Courtine, J.-F., Suarez et le système de la métaphysique, París, Épiméthée, 2015.

Crombie, A. C., Historia de la ciencia: de San Agustín a Galileo/2, Madrid, Alianza, 1987.

Darge, R., "Suárez on the Subject of Metaphysics", en V. Salas and R. Fastiggi (eds.), A Companion to Francisco Suárez, Leiden, Brill, 2014.

De Almeida Oliveira, J., "Francisco Suárez: a metafísica na aurora da modernidade", Theoria - Revista Eletrônica de Filosofia, 2/4 (2010), pp. 44-57.

Esposito, C., "Suárez, filósofo barroco", Cauriensia 12 (2017), pp. 25-42. Fabro, C., Historia de la Filosofía I, Madrid, Rialp, 1965.

Florido, F. L., "Una estructura filosófica en Historia de la Filosofía”, Anales del Seminario de Historia de la Filosofía 17 (2000), pp. 195-216.

Florido, F. L., Las filosofías en la Edad Media. Crisis, controversias y condenas, Madrid, Biblioteca Nueva, 2010.

${ }^{33}$ F. Suárez, D.M., Ratio et Discursus totius operis: “Quemadmodum fieri nequit ut quis Theologus perfectus evadat, nisi firma prius metaphysicae jecerit fundamenta, ita intellexit semper, operae pretium fuisse ut [...] opus hoc, quod nun, Christiane lector, tibi offero, diligenter elaboratum praemitterem." Cfr. V. Salas, "The theological Orientation of Francisco Suárez's Metaphysics”, Pensamiento 74/279 (2018), 7-29. 
Florido, F. L., "El debate sobre la modernidad de la filosofía medieval", Cauriensia 12 (2017), pp. 467-489.

Gilson, E., El ser y los filósofos, Pamplona, Eunsa, 1979.

Gilson, E., Langan, T., Filosofía Moderna, Barcelona, Emecé, 1963.

Guerrero Navarrete, Y., "Los contenidos de la ciencia y los progresos de la ciencia en la Edad Media", Arbor, CLIX/625 (1998), pp. 69-107.

Guy, A., Historia de la filosofía española, Barcelona, Anthropos, 1985.

Hale, J. R., La Europa del Renacimiento 1480-1520, Madrid, Siglo XXI, 2016.

Lázaro Pulido, M.; Idoya Zorroza, M., "Memoria peninsular de un legado para el siglo XXI: Francisco Suárez (1617-2017)”, Pensamiento 74/279 (2018), pp. 299-318.

Lorenz, D., "Sobre algunos disensos, progresos y crisis en la historia de la metafísica tomista”, Revista Philosophica 26 (2003), pp. 1-16.

Mendoza, J.M.F., "Un ítem central en la doctrina científica de Francisco Suárez: del subiectum al obiectum como sustrato de cada ciencia especulativa, Rivista di Filosofia Neo-Scolastica CXI/3 (2019), pp. 607-623.

Parker, G., Europa en crisis 1598-1648, Madrid, Siglo XXI, 2017.

Pereira, J., Suárez between Scholasticism and Modernity, Wisconsin, Marquette University Press, 2006.

Pérez San Martín, H., "Cuestiones previas al estudio de las Disputaciones Metafísicas del P. Francisco Suárez", Cuadernos Salmantinos de Filosofía 24 (1997), pp. 25-49.

Poncela González, Á., “Aristóteles y los Jesuitas. La génesis corporativa de los cursus philosphicus”, Cauriensia 6 (2011), pp. 65-101.

Prieto López, L., "Res, aliquid y nihil en Suárez y la filosofía moderna", Anales del seminario de historia de la filosofía, 30/1 (2013), pp. 49-69.

Prieto López, L., "La impronta escotista en la metafísica de Suárez: conocimiento intuitivo, actualidad de la materia prima e hipostatización del accidente", Logos. Anales del seminario de Metafísica 50 (2017), pp. 207-227.

Rodríguez-San Pedro de Bezares, L. E., La Universidad Salmantina del Barroco, período 1598-1625, t. II: régimen docente y atmósfera intelectual, España, Universidad de Salamanca, 1986.

Salas, V., "The theological Orientation of Francisco Suárez's Metaphysics", Pensamiento 74/279 (2018), pp. 7-29.

Sanz Santacruz, V., "Filosofía y teología en Francisco Suárez”, en Á. L. González (ed.), La intermediación de filosofía y teología. Santo Tomás de Aquino, San Buenaventura, Nicolás de Cusa, Suárez, Pamplona, Cuadernos de Anuario Filosófico n. 241, 2011. 
South, J. B., "Some Themes in Suárez's Account of the Separated Soul”, Pensamiento 74/279 (2018), pp. 63-74.

Suárez, F., Disputaciones Metafísicas, Madrid, Biblioteca hispánica de filosofía, 1960. [Ed. y trad. de S. Rábade Romeo, S. Caballero Sánchez y A. Puigcerver Zanón].

Suárez, F., Disputaciones Metafísicas, Madrid, Tecnos, 2011. [Presentación de S. Rábade Romeo y Estudio Preliminar de F. L. Florido]. 